\title{
Effect of Peptidase Inhibitors on Dynorphin A (1-17) or (1-13)-Induced Antinociception and Toxicity at Spinal Level
}

\author{
Mitsumasa Matsuda1, Masanobu Yoshikawa2*, Takugi Kan1, Mariko Watanabe1, Junko Ajimi1, \\ Shigeru Takahashi2, Masaaki Miura1,3, Kenji Ito1, Hiroyuki Kobayashi², Toshiyasu Suzuki1
}

${ }^{1}$ Department of Anesthesiology, School of Medicine, Tokai University, Isehara, Japan

${ }^{2}$ Department of Clinical Pharmacology, School of Medicine, Tokai University, Isehara, Japan

${ }^{3}$ Department of Anesthesiology, Hiratsuka City Hospital, Hiratsuka, Japan

Email: ${ }^{\star}$ yoshikawa@is.icc.u-tokai.ac.jp

How to cite this paper: Matsuda, M., Yoshikawa, M., Kan, T., Watanabe, M., Ajimi, J., Takahashi, S., Miura, M., Ito, K., Kobayashi, H. and Suzuki, T. (2017) Effect of Peptidase Inhibitors on Dynorphin A (1-17) or (1-13)-Induced Antinociception and Toxicity at Spinal Level. Pharmacology \& Pharmacy, 8, 33-51.

https://doi.org/10.4236/pp.2017.82003

Received: January 11, 2017

Accepted: February 10, 2017

Published: February 13, 2017

Copyright $\odot 2017$ by authors and Scientific Research Publishing Inc. This work is licensed under the Creative Commons Attribution International License (CC BY 4.0).

http://creativecommons.org/licenses/by/4.0/

c. (i) Open Access

\begin{abstract}
Our group has earlier demonstrated that three enzymes sensitive to peptidase inhibitors (PIs), amastatin (A)-, captopril (C)-, and phosphoramidon (P), played an important role in inactivation of enkephalins at the spinal level. Dynorphin-converting enzyme (DCE) hydrolyzes dynorphin (Dyn) A (1-17) or Dyn A (1-13) mainly at the $\mathrm{Arg}^{6}-\mathrm{Arg}^{7}$ bond. Dynorphin A and its derived peptides interact with opioid and glutamate receptors at their $\mathrm{N}$ - and C-terminals, respectively. The purpose of the present study was to evaluate the antinociceptive potency and toxicity of intrathecal administered Dyn A (1-17), Dyn A (1-13), or Dyn A (1-6) under pretreatment with ACP and/or the DCE inhibitor p-hydroxymercuribenzoate (PHMB). The effect of these PIs on Dyn A (1-17)-induced inhibition of electrically-evoked contractions in mouse vas deferens was also investigated. The inhibitory potency of Dyn A (1-17) on electrically-evoked contractions in mouse vas deferens under pretreatment with ACP was higher than that with AC, AP, or CP. Pretreatment with ACP augmented Dyn A (1-17) or (1-13)-induced antinociception by approximately 50- or 30-fold with no sign of allodynia when administered intrathecally at low doses. Pretreatment with ACP and PHMB induced neuropathy. These findings showed that intrathecal administration of low-dose Dyn A (1-17) or DynA (1-13) increased antinociception under pretreatment with ACP, but without signs of allodynia in rat.
\end{abstract}

\section{Keywords}

Dynorphin A, Peptidase, Dynorphin-Converting Enzyme, Antinociception, Allodynia 


\section{Introduction}

Dynorphin (Dyn) A (1-17) and (1-13) interacts with both opioid and N-methyl$\mathrm{D}$-aspartate (NMDA) receptors: their N-terminals activate the former with high affinity, while its C-terminals activate the latter with low affinity [1] [2] [3] [4]. In fact, intrathecal (i.t.) low dose (0.5 - 2 nmol) administration of Dyn A induced an antinociceptive effect [5] [6], whereas that at a high dose induced longlasting mechanical allodynia and motor dysfunction [7] [8] [9] [10].

Three peptidases, an aminopeptidase N (APN), a dipeptidylcarboxypeptidase, and neutral endopeptidase-24.11 (NEP), play an important role in degradation of opioid peptides. High-performance liquid chromatography revealed that [Leu $\left.{ }^{5}\right]-$ enkephalin (LE) [11] or Dyn A (1-8) [12] remained intact in the presence of a mixture of peptidase inhibitors (PIs) when incubated with membrane preparation, but was completely hydrolyzed after incubation in their absence.

Preparations isolated in vitro allow a drug to be quantified and its efficacy, potency, and affinity compared more accurately than can be done with in vivo methods [13]. Earlier research on the inhibitory potency of LE or Dyn A (1-8) against electrically-evoked contractions in mouse vas deferens (MVD) demonstrated that it was enhanced by exposure to various combinations of amastatin (A), captopril (C), and phosphoramidon (P) [14] [15]. These results correspond with the results of the previous in vivo studies showing that intracerebroventricular (i.c.v.) administration of ACP increased LE-, Dyn A (1-8)-, and Dyn A (1-17)-induced antinociception by more than 500- [14], 100- [16], and 30-fold [17], respectively.

Dynorphin-converting enzyme (DCE) hydrolyzes Dyn A mainly at the $\mathrm{Arg}^{6}$ $\mathrm{Arg}^{7}$ bond, resulting in the production of $\mathrm{N}$ - and $\mathrm{C}$-terminal region peptide fragments, and this enzyme is not inhibited by ACP [18]. Matrix-Assisted Laser Desorption Ionization Time-of-Flight Mass Spectrometry (MALDI-TOF-MS) identified N-terminal peptide fragment Dyn A (1-6) from Dyn A (1-17), but not the corresponding C-terminal peptide fragment, Dyn A (7-17), after incubation of Dyn A (1-17) with membrane fraction from rat midbrain or caudate putamen under pretreatment with ACP [17] [19]. These results suggest that C-terminal peptide fragments such as DynA (7-17) are catabolized, generating shorter, extremely weak, non-toxic products, particularly under pretreatment with ACP [17].

The purpose of the present study was to evaluate antinociceptive potency and toxicity with i.t. administration of Dyn A (1-17), Dyn A (1-13), or Dyn A (1-6) under pretreatment with ACP and/or DCE inhibitor p-hydroxymercuribenzoate (PHMB) in rat spinal cord under physiological conditions. In an attempt to further characterize the pharmacological action of PIs, the effect of ACP on Dyn A (1-17)-induced inhibition of electrically-evoked contractions in MVD was also evaluated.

\section{Materials and Methods}

The present animal experiments were performed in strict accordance with the guidelines (http://www.u-tokai.ac.jp/about/concept/guidance.html) of Tokai Uni- 
versity and with the approval of the Animal Investigation Committee of this institute.

\subsection{Chemicals}

Dynorphin A (1-17), Dyn A (1-13), A, and P were purchased from Peptide Institute Inc. (Minoh, Japan). Dyn A (1-6) was purchased from Phoenix Pharmaceuticals, Inc. (Mannheim, Germany). Captopril, D-Phe-Cys-Tyr-D-Trp-OrnThr-Pen-Thr- $\mathrm{NH}_{2}$ (CTOP, a $\mu$-opioid receptor antagonist), nor-binaltorphiminedihydrochloride (nor-BNI, a $\kappa$-opioid receptor antagonist), and naltrindole hydrochloride (NTI, a $\delta$-opioid receptor antagonist) were purchased from SIGMA Japan (Tokyo, Japan). Naloxone hydrochloride (NOX, a non-selective opioid receptor antagonist) was purchased from Daiichi-Sankyo Company, Limited (Tokyo, Japan). P-hydroxymercuribenzoate was purchased from Merck Japan (Tokyo, Japan). All chemicals apart from nor-BNI, NTI, and PHMB were dissolved in saline. Nor-BNI and NTI were dissolved in water. The PHMB was dissolved in saline with $0.1 \mathrm{~N}-\mathrm{NaOH}$ up to a $\mathrm{pH}$ of 9.0. The solution for all drugs used was prepared to the desired concentration just before use. In accordance with the method of earlier studies, CTOP (3 nmol, i.t.), nor-BNI (20 mg/kg, subcutaneously), and NTI (66 nmol, i.t.) were injected $15 \mathrm{~min}, 30 \mathrm{~min}$, and $24 \mathrm{~h}$, respectively, before i.t. administration of the PIs [20] [21] [22] [23].

\subsection{In Vitro Isolated Preparations}

Male ICR JCL mice (30 - 40 g each; Nihon Clea, Tokyo, Japan) were used. Mouse vas deferens was harvested and prepared for electrical stimulation as described previously [24]. The percent (\%) inhibition of stimulated muscle twitch produced by each opioid was plotted against its log concentration to determine the $\mathrm{IC}_{50}$ (concentration required to produce $50 \%$ inhibition of the twitch). When investigating the effect of PIs on Dyn A (1-17)-induced inhibition of contractions, a period of 3 min was given before administration of Dyn A (1-17). The \% difference shown in the tables was calculated as follows: $\%$ difference $=\left[\left(\mathrm{IC}_{50}\right.\right.$ before each treatment $-\mathrm{IC}_{50}$ after each treatment)/IC ${ }_{50}$ before each treatment] $\times$ $100[24]$.

\subsection{Intrathecal Administration}

Intrathecal catheters were implanted in Male Wistar rats (180 - 220 g each; Nihon Clea, Tokyo, Japan) under inhalation anesthesia with nitrous oxide, oxygen, and isoflurane (2\%) as described previously [17] [25]. After surgery, all rats were housed individually in a temperature- and light-controlled environment with free access to food and water. Only rats with normal motor function and behavior were used for the experiments 7 days later. Drugs were injected at a volume of $10 \mu$ followed by $10 \mu \mathrm{l}$ saline over $1 \mathrm{~min}$.

\subsection{Tail-Flick Test}

The investigators were blind to all drug treatments carried out in these experiments. Induction of antinociception by Dyn A (1-17), Dyn A (1-13), or Dyn A 
(1-6) was measured by the tail immersion assay, with $55^{\circ} \mathrm{C}$ as the nociceptive stimulus [26] [27]. The latency to flick the tail was measured as described previously [17]. A cut-off time of $5 \mathrm{sec}$ was used to prevent any injury to the tail. The $\%$ of maximal possible effect (MPE) for each animal at each time was calculated using the following formula: \%MPE $=[($ test latency - baseline latency $) /(5-$ baseline latency) $] \times 100$. The area under the curve (AUC) value for the antinociceptive action of each drug was also calculated in some of the experiments.

\subsection{Von Frey Test}

The threshold for tactile allodynia was measured with a series of von Frey filaments (von Frey Filaments; Bioseb, Vitrolles, France), ranging from 2.44 to 5.88 (0.03 - 60.0 g), according to the methods of Park et al. [28] and Zhu et al. [29]. The rats were placed in individual transparent plastic boxes with a wire mesh floor at least $15 \mathrm{~min}$ before testing began to allow acclimatization to the environment. The filaments were pushed against the plantar surface of the right hind paw. Tactile thresholds were measured at intervals before and after administration of drugs. Results were reported as the mean value of 4 readings from the right hind paw in each rat.

\subsection{Animal Experimental Protocol}

\subsubsection{Dyn A-Dependent Antinociception with or without ACP by Dose} Ten minutes following i.t. administration of ACP or saline, Dyn A (1-17), Dyn A (1-13), Dyn A (1-6), or saline was administered by the same route. To determine whether the antinociceptive effect increased with i.t. administration of ACP (10 nmol each), the rats were tested in the following groups: Group 1, Dyn A (1-17) (0.03 - $1 \mathrm{nmol}$ ) alone or with ACP; Group 2, Dyn A (1-13) (0.1 - $3 \mathrm{nmol})$ alone or with ACP; and Group 3, Dyn A (1-6) (0.3 - $3 \mathrm{nmol})$ alone or with ACP.

\subsubsection{Combination of Dyn A (1-17) and PHMB Together with ACP}

Ten minutes following i.t. administration of PHMB and ACP, Dyn A (1-17) (0.3 nmol) was administered intrathecally. To determine whether the antinociceptive effect of Dyn A (1-17) was increased by joint administration of PHMB and ACP, the rats were tested in the following groups: Group 1, Dyn A (1-17) alone; Group 2, Dyn A (1-17) with ACP; Group 3, Dyn A (1-17) with PHMB; and Group 4, Dyn A (1-17) in combination PHMB and ACP.

\subsubsection{Selective or Non-Selective Opioid Receptor Antagonists}

To investigate the effect of opioid receptor antagonists on Dyn A (1-17) (0.3 $\mathrm{nmol}$ ) or DynA (1-13) (0.3 nmol)-induced antinociception under pretreatment with ACP, NOX (1 mg/kg, subcutaneously), CTOP (3 nmol, i.t.) [22], NTI (66 nmol, i.t.) [21], and nor-BNI (20 $\mathrm{mg} / \mathrm{kg}$, subcutaneously) [23] were injected at $20 \mathrm{~min}, 15 \mathrm{~min}, 30 \mathrm{~min}$, and $24 \mathrm{hr}$, respectively, before i.t. administration of Dyn A (1-17) or Dyn A (1-13).

\subsection{Statistical Analyses}

The results are given as the mean and standard error of the mean (S.E.M.) of the 
data. The statistical analysis was conducted using computer software (Prism, version 6.0 c, Graph Pad Software, San Diego, CA, USA) for a comparison across experimental conditions. When a significant difference among the \%MPE data after drug administration was obtained in a two-way (drugs and time) repeated measures analysis of variance (ANOVA), Dunn's multiple comparison test was applied to determine the significance at each time point. When a significant difference was observed in the AUC data among the groups in a two-way (drugs and dose) repeated ANOVA, Dunn's multiple comparison test was applied to determine the significance at each dose. When a significant difference within groups was obtained in the Kruskal-Wallis test, Dunn's comparison test was applied to determine significance.

\section{Results}

\subsection{Enhanced Effect of PIs in Paired Combinations or all Together on Dyn A (1-17)-Induced Inhibition in Isolated Preparation}

The results showed that Dyn A (1-17) significantly inhibited electrically-evoked contractions in MVD. The inhibitory potency of Dyn A (1-17) was dose-dependently augmented by ACP (Table 1). Administration of paired combinations $(2 \mu \mathrm{M}$ each of AP, AC, or $\mathrm{CP})$ or all three PIs together $(2 \mu \mathrm{M} \mathrm{ACP})$ revealed that any two combination or ACP increased Dyn A (1-17)-induced inhibition of electrically-evoked contractions in MVD. This effect was significantly stronger with ACP than with $\mathrm{CP}$; it was also stronger than with administration of AP or AC, but not significantly so (Table 2 ).

Table 1. $\mathrm{IC}_{50}$ values and ratio of potency of Dyn A (1-17) under pretreatment of ACP.

\begin{tabular}{ccc}
\hline $\mathrm{ACP}(\mu \mathrm{M}$ each $)$ & $\mathrm{IC}_{50}(\mathrm{nM})$ & Ratio of potency \\
\hline 0 & $11.37 \pm 3.97$ & \\
1 & $4.53 \pm 2.11$ & $2.77 \pm 1.54$ \\
2 & $3.18 \pm 0.97$ & $3.51 \pm 1.27^{\star}$ \\
5 & $3.15 \pm 1.42$ & $3.81 \pm 1.74^{\star}$
\end{tabular}

Each value represents mean \pm S.E.M. of data obtained from four MVD. The ratio of potency was significantly increased in 2 or $5 \mu \mathrm{M} \mathrm{ACP}$ as compared to these in $0 \mu \mathrm{M} \mathrm{ACP} ;{ }^{*} P<0.05$ by Dunn's post-hoc test following Kruskal-Wallis test.

Table 2. $\mathrm{IC}_{50}$ values and ratio of potency of Dyn A (1-17) under pretreatment of combination of PIs.

\begin{tabular}{ccc}
\hline PIs $(2 \mu \mathrm{M}$ each $)$ & $\mathrm{IC}_{50}(\mathrm{nM})$ & Ratio of potency \\
\hline None & $11.37 \pm 3.97$ & \\
$\mathrm{ACP}$ & $3.18 \pm 0.97$ & $3.51 \pm 1.27$ \\
AP & $3.90 \pm 1.53$ & $2.88 \pm 0.86$ \\
AC & $4.64 \pm 1.14$ & $2.30 \pm 0.53$ \\
CP & $6.10 \pm 1.85$ & $1.80 \pm 0.52^{\star}$ \\
\hline
\end{tabular}

Each value represents mean \pm S.E.M. of data obtained from four MVD. The ratio of potency was significantly deceased in $\mathrm{CP}$ as compared to $\mathrm{ACP} ;{ }^{*} P<0.05$ by Dunn's post-hoc test following Kruskal-Wallis test. 


\subsection{Effect of ACP on Dyn A (1-17)- or Dyn A (1-13)-Induced Antinociception}

Change over time in Dyn A (1-17)-induced antinociception with i.t. administration of saline and ACP is shown in Figure 1(a) and Figure 1(b), respectively.

(a)

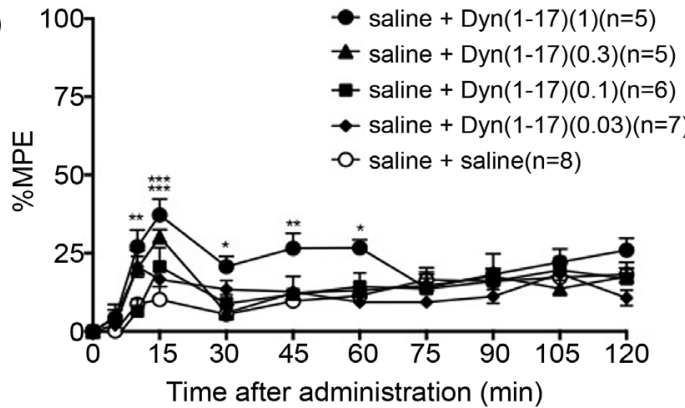

(b)

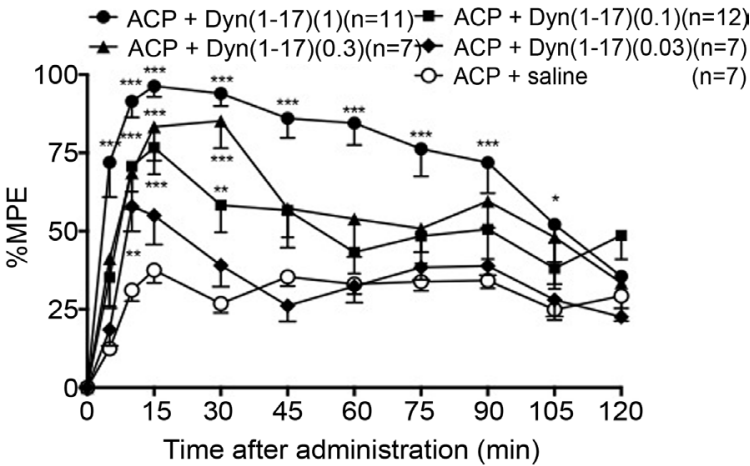

(c)

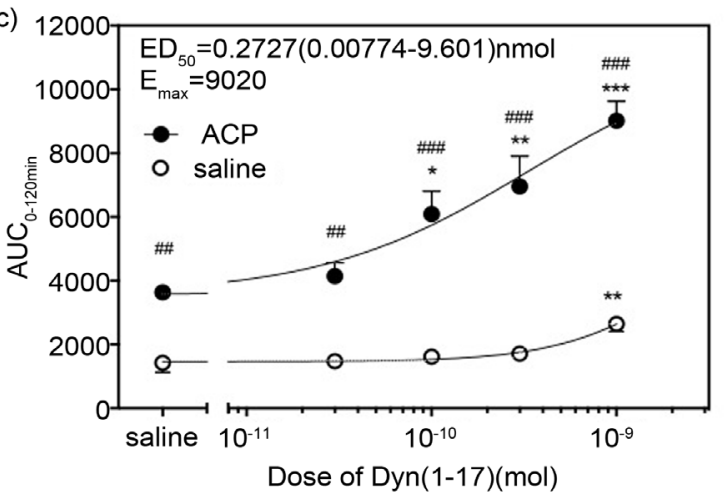

Figure 1. Dose-dependent antinociception by i.t. administration of Dyn A (1-17) under pretreatment with saline or ACP. Upper (a) and middle panels (b) indicate time course of \%MPE of Dyn A (1-17) $(0.03$ - $1 \mathrm{nmol})$ under pretreatment with saline and ACP, respectively. Significantly different from saline-saline or ACP-saline treated control by Dunn's post-hoc test following two-way repeated measures ANOVA; ${ }^{\star} P<0.05,{ }^{* *} P<$ 0.01 , and ${ }^{\star * *} P<0.001$. Lower panel (c) shows $A^{*} C_{0-120 \text { min }}$ for value of \%MPE indicated in upper (a) and middle panels (b). Where asterisks have been placed above $\mathrm{AUC}_{0-120 \mathrm{~min}}$ values for Dyn A (1-17) under pretreatment with ACP, this indicates significant differences in comparison with for saline alone or saline under pretreatment with ACP according to Dunn's post-hoc test following the Kruskal-Wallis test; ${ }^{\star} P<0.05,{ }^{* *} P<0.01$, and ${ }^{\star * *} P<$ 0.001 . Where sharp symbols have been placed above $\mathrm{AUC}_{0-120 \mathrm{~min}}$ values for Dyn A (1-17) under pretreatment with $\mathrm{ACP}$, this indicates significant differences in comparison with those for Dyn A (1-17) under pretreatment with saline according to Dunn's post-hoc test following two-way repeated measures ANOVA; ${ }^{\# \#} P<0.01$ and ${ }^{\# \#} P<0.001$. 
Change over time in Dyn A (1-13)-induced antinociception after i.t. administration of saline and ACP is shown in Figure 2(a) and Figure 2(b), respectively. A prolonged and dose-dependent antinociceptive effect was observed on the tail-flick response by administration of Dyn A (1-17) and Dyn A (1-13).
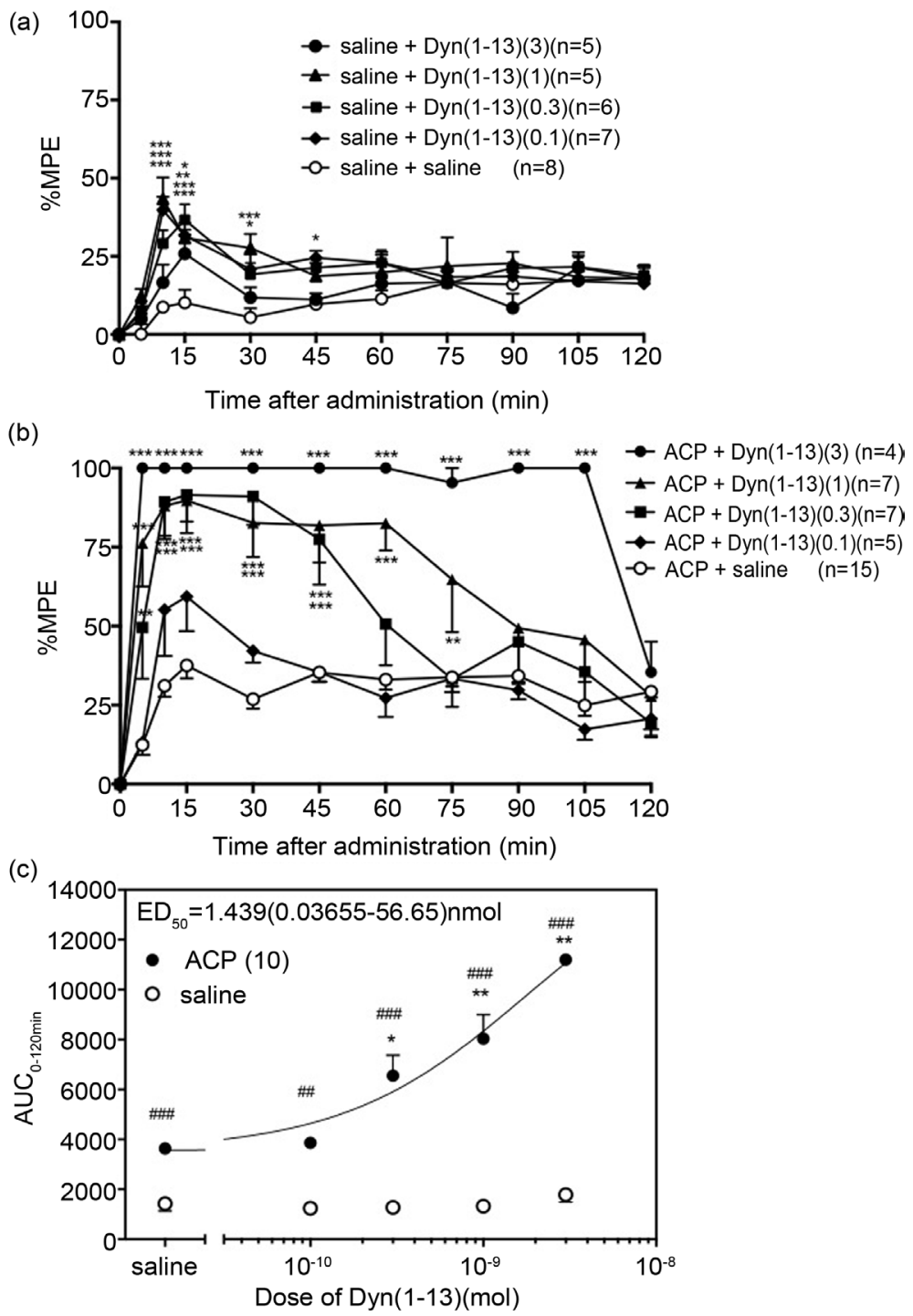

Figure 2. Dose-dependent antinociception by i.t. administration of Dyn A (1-13) under pretreatment with saline or ACP. Upper (a) and middle panels (b) indicate time course of \%MPE of Dyn A (1-13) (0.1 - 3 nmol) under pretreatment with saline and ACP, respectively. Significantly different from saline-saline treated control in Dunn's post-hoc test following two-way repeated measures ANOVA; ${ }^{\star} P<0.05,{ }^{\star *} P<0.01$, and ${ }^{\star * \star} P<$ 0.001. Lower panel (c) shows $\mathrm{AUC}_{0-120 \mathrm{~min}}$ for value of \%MPE indicated in upper (a) and middle panels (b). Where asterisks have been placed above $\mathrm{AUC}_{0-120 \min }$ values for Dyn $\mathrm{A}$ (1-13) under pretreatment with ACP, this indicates significant differences in comparison with for saline alone or saline under pretreatment with ACP according to Dunn's post-hoc test following the Kruskal-Wallis test; ${ }^{\star} P<0.05$ and ${ }^{\star *} P<0.01$. Where sharp symbols have been placed above $\mathrm{AUC}_{0-120 \min }$ values for Dyn A (1-13) under pretreatment with ACP, this indicates significant differences in comparison with those for Dyn A (1-13) under pretreatment with saline according to Dunn's post-hoc test following two-way repeated measures ANOVA; ${ }^{\# \#} P<0.01$ and ${ }^{\# \# \#} P<0.001$. 
The onset, offset, and duration of the antinociceptive effect induced by i.t. administration of 0.1 nmol Dyn A (1-17) under pretreatment with ACP was the same as that with $5 \mathrm{nmol}$ Dyn A (1-17) alone (Figure 3(a)). Administration of 0.1 nmol Dyn A (1-17) under pretreatment with ACP yielded an $\mathrm{AUC}_{0-120 \mathrm{~min}}$ value for \%MPE similar to that with 5 nmol Dyn A (1-17) alone (Figure 3(b)). The onset, offset, and duration of the antinociceptive effect induced by i.t. administration of 0.3 nmol Dyn A (1-13) under pretreatment with ACP was similar to that with $10 \mathrm{nmol}$ Dyn A (1-13) alone (Figure 3(c)). Administration of 0.3 nmol Dyn A (1-13) under pretreatment with ACP yielded an $\mathrm{AUC}_{0-120 \text { min }}$ value for \%MPE similar to that with $10 \mathrm{nmol}$ Dyn A (1-13) alone (Figure 3(d)).

Intrathecal administration of Dyn A (1-17) under pretreatment with ACP induced a 50-fold increase in the antinociceptive effect on the tail-flick response, while that of Dyn A (1-13) increased it 30-fold.

\subsection{Effect of ACP on Dyn A (1-6)-Induced Antinociception}

Figure 4(a) shows change over time in Dyn A (1-6)-induced antinociception after i.t. administration of saline, while Figure 4 (b) shows that with ACP. A
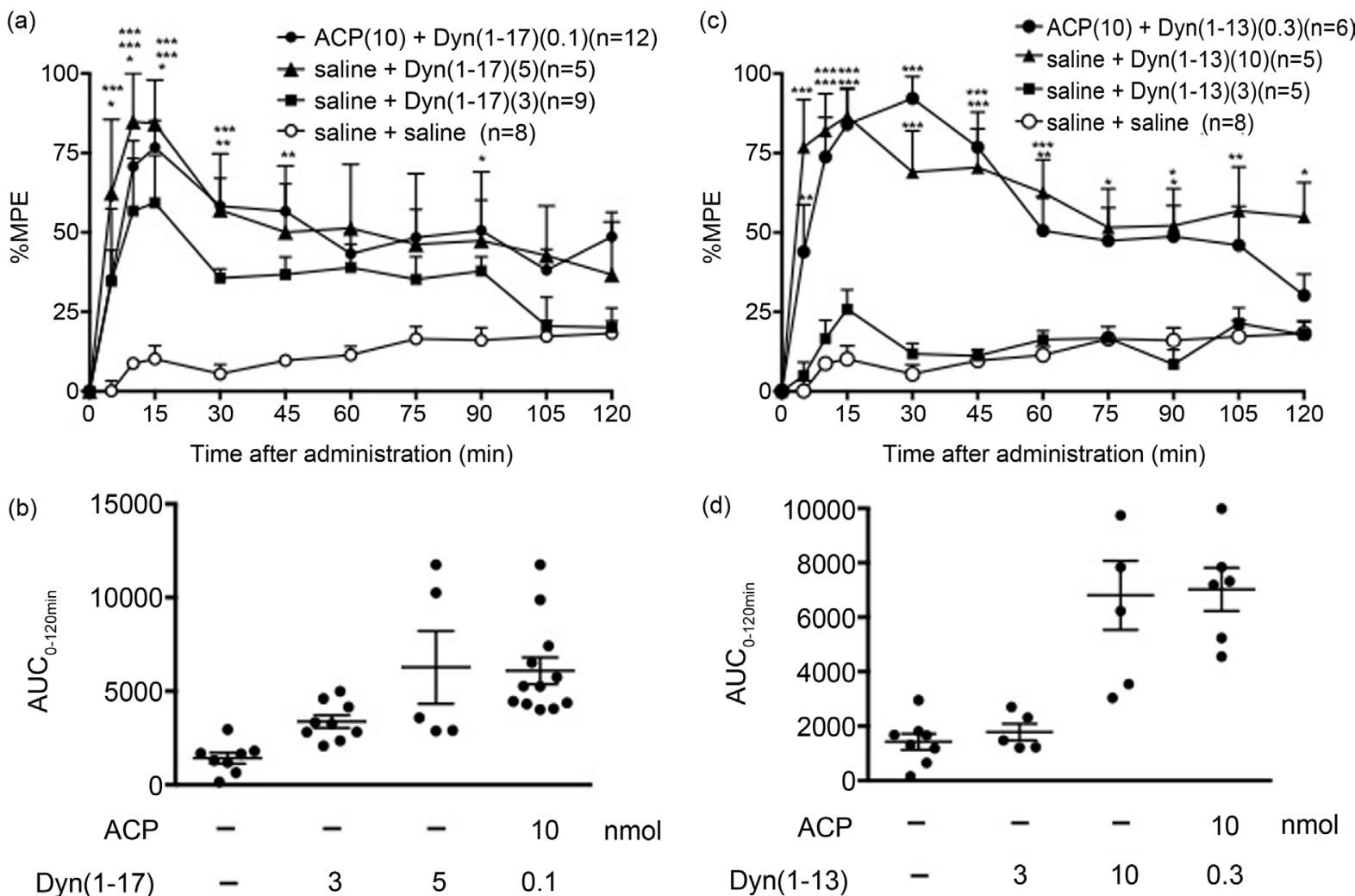

Figure 3. Potentiating effect of ACP on antinociception induced by i.t. administration of Dyn A (1-17) or Dyn A (1-13). Upper panel (a) indicates time course of \%MPE of Dyn A (1-17) (0.1 nmol) under pretreatment with ACP (10 nmol each) and Dyn A (1-17) (3 or $5 \mathrm{nmol}$ ) under pretreatment with saline. Upper panel (c) indicates time course of \% MPE of Dyn A (1-13) $(0.3 \mathrm{nmol})$ under pretreatment with ACP (10 nmol each) and Dyn A (1-13) (3 or $10 \mathrm{nmol})$ under pretreatment with saline. Significantly different from saline-saline treated control according to Dunn's post-hoc test following two-way repeated measures ANOVA; ${ }^{\star} P<0.05,{ }^{\star *} P<0.01$, and ${ }^{\star * \star} P<0.001$. Lower panel (b) and (d) shows $\mathrm{AUC}_{0-120 \mathrm{~min}}$ for value of $\%$ MPE indicated in upper panel (a) and (c), respectively. 

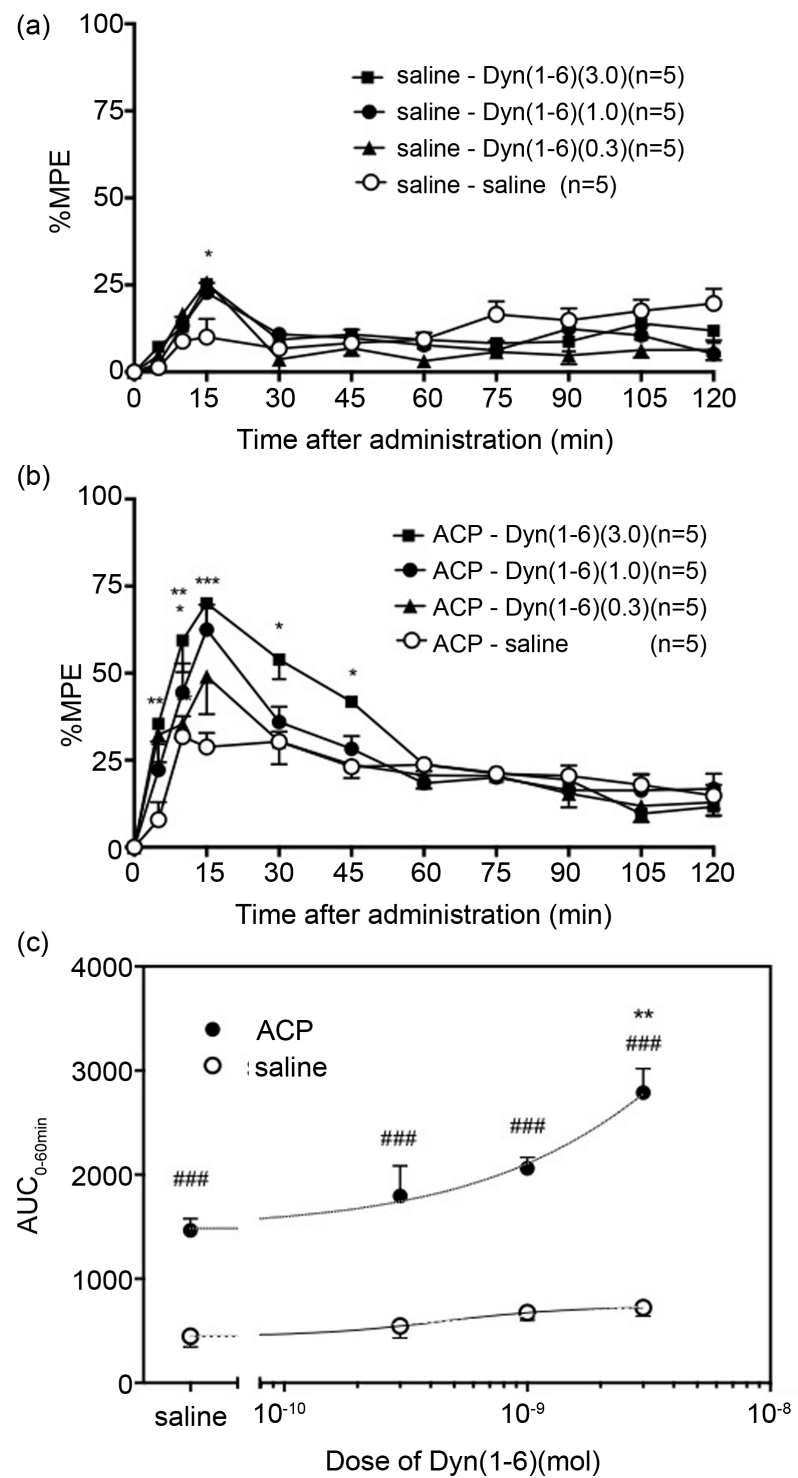

Figure 4. Dose-dependent antinociception by i.t. administration of Dyn A (1-6) under pretreatment with saline or ACP. Upper (a) and middle panels (b) indicate time course of \%MPE of Dyn A (1-6) (0.3 - 3 nmol) under pretreatment with saline and ACP, respectively. Significantly different from saline-saline treated control in Dunn's post-hoc test following two-way repeated measures ANOVA; ${ }^{*} P<0.05$, ${ }^{* *} P<0.01$, and ${ }^{* * *} P<0.001$. Lower panel (c) shows $\mathrm{AUC}_{0-60 \mathrm{~min}}$ for value of \%MPE indicated in upper (a) and middle panels (b). Where asterisks have been place above $\mathrm{AUC}_{0-60 \min }$ values for Dyn $\mathrm{A}$ (1-6) under pretreatment with $\mathrm{ACP}$, this indicates significant differences in comparison with saline under pretreatment with ACP according to Dunn's post-hoc test following the Kruskal-Wallis test; ${ }^{*} P<0.01$. Where sharp symbols have been place above $\mathrm{AUC}_{0-60 \mathrm{~min}}$ values for Dyn A (1-6) under pretreatment with ACP, this indicates significant differences in comparison with that for Dyn A (1-6) under pretreatment with saline according to Dunn's post-hoc test after two-way repeated measures ANOVA; ${ }^{\# \# \#} P<0.001$.

prolonged and dose-dependent antinociceptive effect was observed on the tailflick response with administration of Dyn A (1-6). The $\mathrm{AUC}_{0-60 \mathrm{~min}}$ value demonstrated significantly greater induction of antinociception with 3 nmol Dyn A (1-6) under pretreatment with ACP than with ACP alone (Figure 4(c)). 


\subsection{Effect of Antagonists on Dyn A (1-17)- or Dyn A (1-13)-Induced Antinociception under Pretreatment with ACP}

The antinociceptive potency of Dyn A (1-17) or Dyn A (1-13) under pretreatment with ACP was significantly attenuated by NOX, CTOP, or nor-BNI; it was also was attenuated by NTI, but not significantly so (Figure 5 and Figure 6).

\subsection{Effect of PHMB on Dyn A (1-17)-Induced Antinociception}

The antinociceptive potency of $0.3 \mathrm{nmol}$ Dyn A (1-17) under pretreatment with ACP was significantly higher than that of 0.3 nmol Dyn A (1-17) alone or with PHMB (10 nmol) (Figure 7). The antinociceptive potency of $0.3 \mathrm{nmol}$ Dyn A (1-17) under pretreatment with PHMB and ACP was approximately equal to that of 0.3 nmol Dyn A (1-17) under pretreatment with ACP alone (Figure 7). Ten minutes following i.t. administration of PHMB and ACP, $0.3 \mathrm{nmol}$ Dyn A (1-17) was administered in 6 rats. Two of the rats showed no abnormal signs as a result. Meanwhile, subtle and transient paralysis occurred in two more, and these animals showed the lowest $\mathrm{AUC}_{0-120 \mathrm{~min}}$ values in the tail flick test. The results

(a)

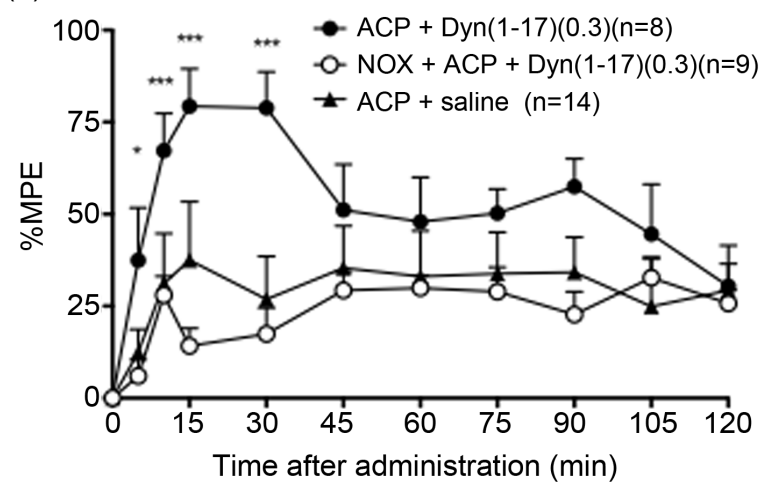

(b)

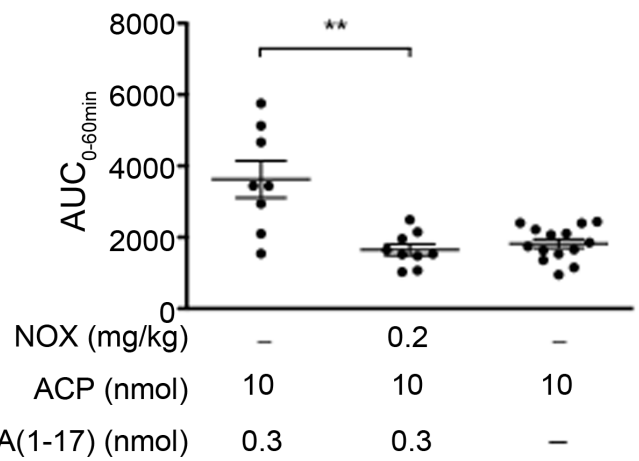

(c)

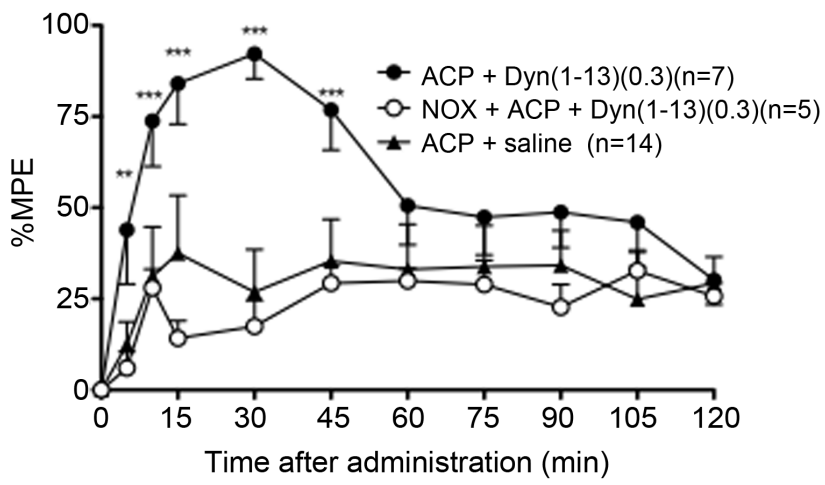

(d)

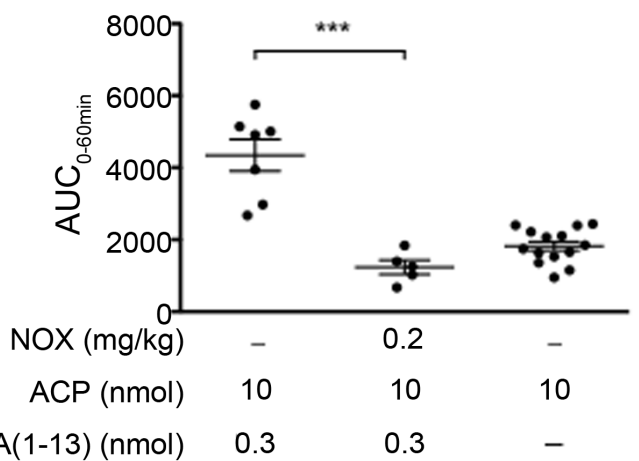

Figure 5. Effect of non-selective opioid receptor antagonist NOX on antinociceptive potency of Dyn A (1-17) or Dyn A (1-13) under pretreatment with ACP. Upper panels (a) and (c) indicate time course of \%MPE of Dyn A (1-17) (0.3 nmol) and DynA (1-13) $(0.3 \mathrm{nmol})$-induced antinociception under pretreatment with ACP following administration of NOX $(0.2 \mathrm{mg} / \mathrm{kg}), \mathrm{respec}-$ tively. Significantly different from NOX-administrated group according to Dunn's post-hoc test following two-way repeated measures ANOVA; ${ }^{\star} P<0.05,{ }^{* *} P<0.01$, and ${ }^{* *} P<0.001$. Lower panels $(\mathrm{b})$ and $(\mathrm{d})$ show $\mathrm{AUC}_{0-60 \mathrm{~min}}$ for value of \%MPE indicated in upper panels (a) and (c), respectively. Significantly different from NOX-administrated group according to Dunn's post-hoc test following Kruskal-Wallis test; ${ }^{* *} P<0.01$ and ${ }^{\star * *} P<0.001$. 
(a)

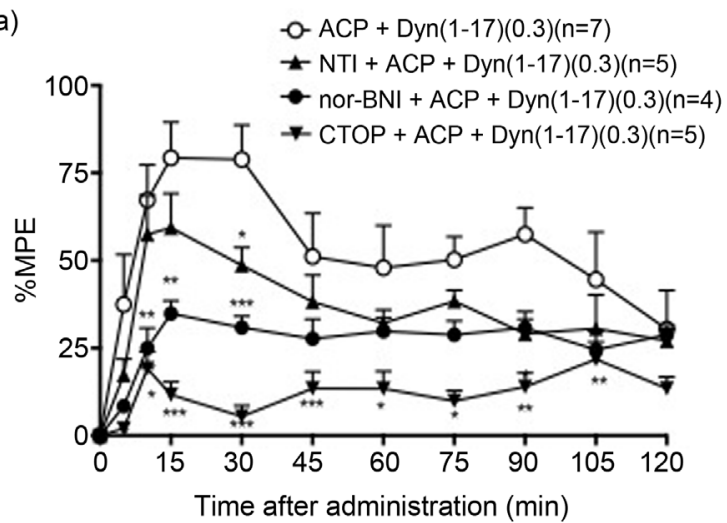

(b)

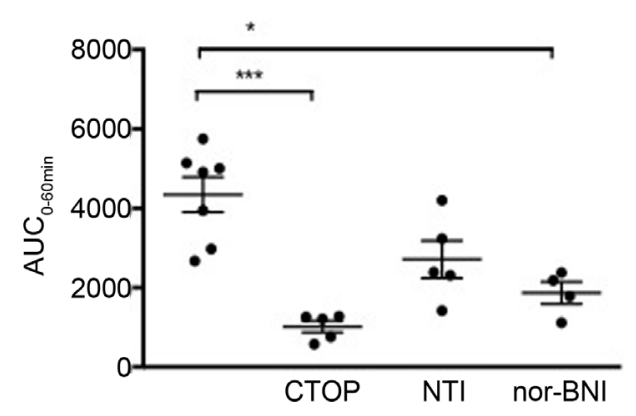

(c)

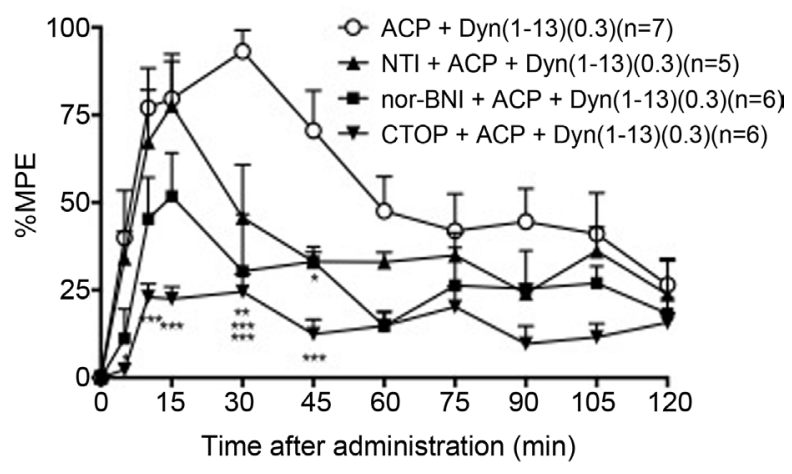

(d)

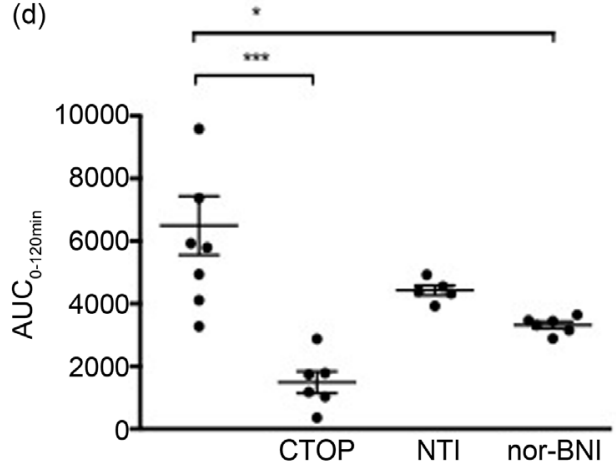

Figure 6. Effect of opioid receptor selective antagonists on antinociceptive potency of Dyn A (1-17) or Dyn A (1-13) under pretreatment with ACP. Upper panels (a) and (c) indicate time course of \%MPE of Dyn A (1-17) (0.3 nmol) and Dy$\mathrm{nA}(1-13)$ (0.3 nmol)-induced antinociception under pretreatment with ACP following administration of three opioid receptor antagonists CTOP (3 nmol), nor-BNI $(20 \mathrm{mg} / \mathrm{kg})$, or NTI (66 nmol), respectively. Significantly different from Dyn A (1-17) or Dyn A (1-13) under pretreatment with ACP according to Dunn's post-hoc test following two-way repeated measures ANOVA; ${ }^{*} P<0.05,{ }^{* *} P<0.01$, and ${ }^{* *} P<0.001$. Lower panels (b) and (d) show $\mathrm{AUC}_{0-60 \mathrm{~min}}$ and $\mathrm{AUC}_{0-120 \mathrm{~min}}$ for value of \%MPE indicated in upper panels (a) and (c), respectively. Significantly different from Dyn A (1-17) under pretreatment with ACP according to Dunn’s post-hoc test following Kruskal-Wallis test; ${ }^{\star} P<0.05$ and ${ }^{\star * \star} P<0.001$.

of the tail flick and von Frey tests in all of four of these animals are reported here. The two remaining rats, however, showed prolonged and severe paralysis, making both the tail flick and von Frey test unviable. Thus, 4 out of 6 rats showed some signs of neuropathy following i.t. administration of $0.3 \mathrm{nmol}$ Dyn A (1-17) under pretreatment with both PHMB and ACP.

\subsection{ACP Attenuates Allodynia Induced by i.t. Administration of Dyn A (1-17)}

No significant differences were observed in the baseline threshold stimulus between each group before administration of Dyn A (1-17) (3 or $5 \mathrm{nmol}$ ) alone or Dyn A (1-17) (0.1, $0.3 \mathrm{nmol})$ with ACP and/or PHMB (10 nmol). The threshold stimulus intensity required to evoke withdrawal was in the order of 4.93 to 5.88 $(8.0$ - $60.0 \mathrm{~g})$ in normal rat (Figure 8). Intrathecal administration of Dyn A (1-17) $(3,5 \mathrm{nmol})$ produced significant mechanical allodynia, with tactile thresholds falling from approximately 3.61 to $4.08(0.4-1.0 \mathrm{~g})$ (Figure $8(\mathrm{a})$ ). In contrast, no allodynia was observed with Dyn A (1-17) $(0.1,0.3 \mathrm{nmol})$ with ACP or PHMB (Figure 8). 
(a)

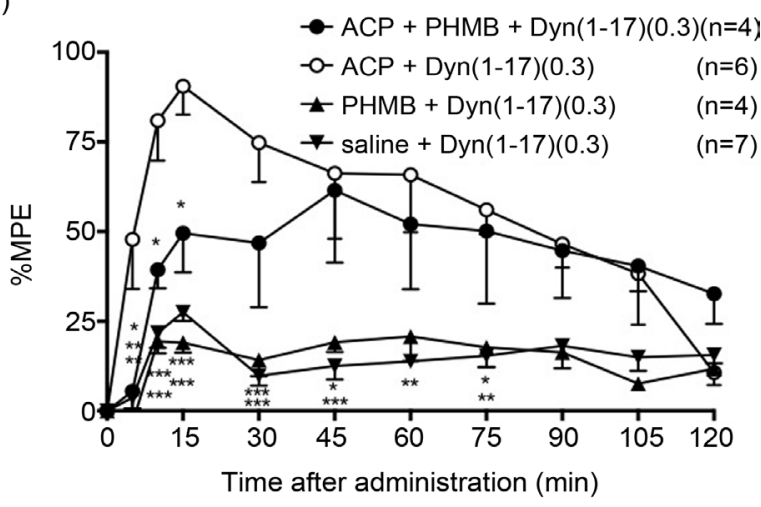

(b)

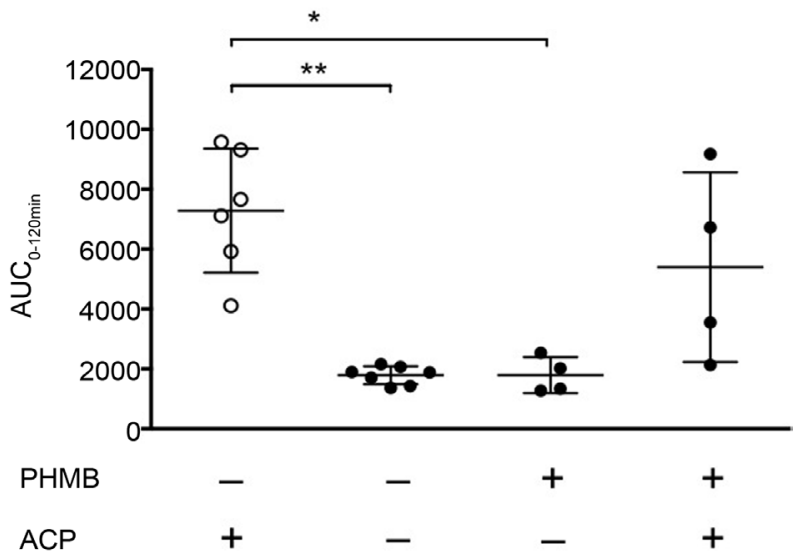

Figure 7. Antinociception by i.t. administration of Dyn A (1-17) under pretreatment with saline or ACP together with/without PHMB. Upper panel (a) indicates time course of \%MPE of Dyn A (1-17) (0.3 nmol) under pretreatment with saline and ACP with and without PHMB, respectively. Significantly different from saline-ACP treated control in Dunn's post-hoc test following two-way repeated measures ANOVA; ${ }^{\star} P<0.05,{ }^{\star \star} P<$ 0.01 , and ${ }^{\star *} P<0.001$. Lower panel (b) shows $\mathrm{AUC}_{0-120 \mathrm{~min}}$ for value of $\% \mathrm{MPE}$ indicated in upper panel (a). Significantly different from saline-ACP treated control according to Dunn's post-hoc test following Kruskal-Wallis test; ${ }^{\star} P<0.05$ and ${ }^{\star *} P<0.01$.

\section{Discussion}

The present results revealed that the antinociceptive potency of Dyn A (1-17), Dyn A (1-13), or Dyn A (1-6) depended on the dose and length of the peptide when administered i.t. in the absence of, or under pretreatment with, ACP. This is in good agreement with the results of earlier studies showing that Dyn A (1-17)-induced antinociception at the supraspinal level was greater than that of Dyn A (1-6) or Dyn A (1-13) at the same dose [17], and that Dyn A (1-17) had a greater analgesic effect than Dyn A (1-13) in the absence of ACP [30]. Pretreatment with ACP increased antinociception with low-dose Dyn A (1-17), with neither hyperalgesia nor paralysis. The present findings then provide further support for the view that C-terminal peptide fragments of Dyn A (1-17), such as Dyn A (7-17), are catabolized into shorter products that are extremely weak toxicity under pretreatment with ACP [17], thus reducing neuropathic symptoms.

Intrathecal administration of Dyn A (1-17) and LE [31] under pretreatment with ACP augmented antinociception by at least 50 - and 100 -fold, respectively. 
(a)

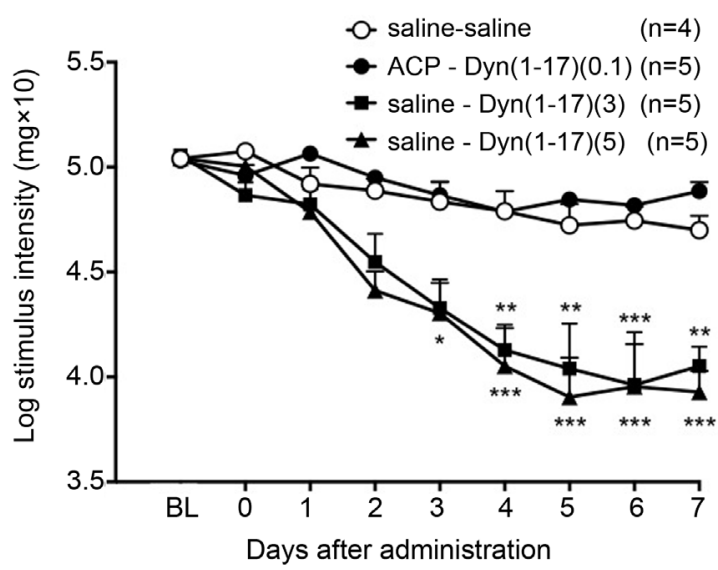

(b)

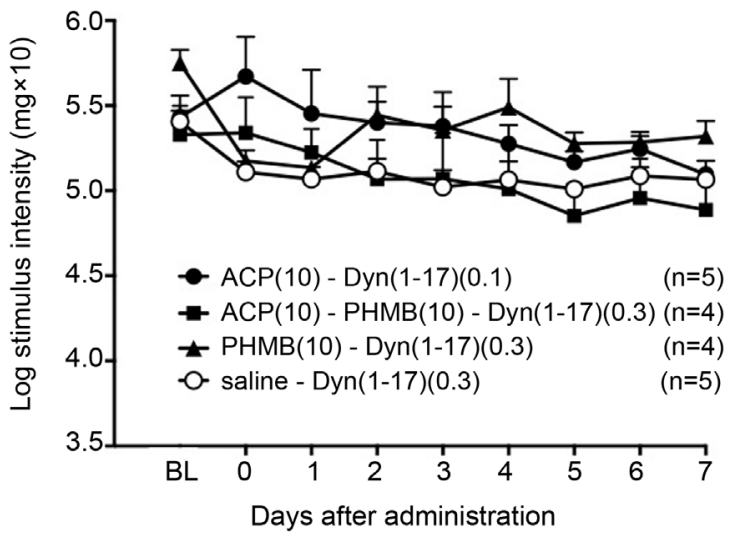

Figure 8. Duration of tactile threshold stimulus intensity required to evoke withdrawal with Dyn A (1-17) $(0.3,3$ or $5 \mathrm{nmol})$ alone or Dyn A (1-17) $(0.1,0.3 \mathrm{nmol})$ with ACP and/or PHMB administration. Upper and lower panels (a) and (b) indicate tactile thresholds measured at intervals by von Frey filaments. Significantly different from Dyn A (1-17) under pretreatment with ACP and/or PHMB according to Dunn's post-hoc test following two-way repeated measures ANOVA; ${ }^{*} P 0.05,{ }^{\star *} P<0.01$ and ${ }^{\star * *} P<0.001$.

These findings coincide well with the results of earlier histological studies showing that the distribution of NEP and APN was highly concentrated in the substantia gelatinosa of the spinal cord, a region closely associated with $\mu$-opioid receptors and enkephalins [32] [33] [34] [35]. Taken together, this suggests that this co-localization of peptidases and opioid peptides plays a critical role in nociception through the latter's inactivation in the spinal cord.

Pretreatment of paired combinations ( $2 \mu \mathrm{M}$ each of AP, AC, or CP) or all three PIs together $(2 \mu \mathrm{M}$ ACP) revealed that AP or ACP significantly increased Dyn A (1-17)-induced inhibition of electrically-evoked contractions in MVD. This effect was significantly stronger with ACP than with AC or CP; it was also stronger than with administration of AP, but not significantly so. These results demonstrate that ACP is required to inhibit degradation of intact Dyn A (1-17), and that any residual pair of peptidases inactivates substantial amounts of Dyn $A$ (1-17). This is in good agreement with the results of an earlier study by this group demonstrating that the antinociceptive potency of Dyn A (1-17) was 
higher under pretreatment with ACP than with any paired combination of these PIs at the supraspinal level [17].

Both the present and earlier studies demonstrated that $\mathrm{LE}\left(\mathrm{IC}_{50}: 1.74 \mathrm{nM}\right)$ [36] showed greater potency than Dyn A (1-17) $\left(\mathrm{IC}_{50}: 4.53 \mathrm{nM}\right)$ under pretreatment with ACP in isolated MVD preparation. On the other hand, Dyn A (1-17) $\left(\mathrm{ED}_{50}\right.$ : $0.272 \mathrm{nmol})$ showed greater potency than $\mathrm{LE}\left(\mathrm{ED}_{50}: 4.5 \mathrm{nmol}\right)$ [31] under pretreatment with ACP in the tail flick test. This discrepancy might be explained by differences in the opioid receptor subtype mainly responsible for each effect between isolated MVD preparation and spinal cord. The inhibitory potency of the $\delta$-opioid receptor agonist in isolated MVD preparation is greater than that of the others [37]. [Leu ${ }^{5}$-enkephalin [38] and Dyn A [1] [39] mainly bind to $\delta$ - and $\kappa$-opioid receptors, respectively, so the inhibitory potency of LE in isolated MVD preparation is greater than that of Dyn A (1-17). In contrast, the present and earlier [31] studies using opioid receptor selective antagonists showed that i.t. administration of LE or Dyn A (1-17) under pretreatment with ACP induced antinociception by $\mu$-opioid receptors, in particular. These results correspond well with those showing that regional distribution of NEP and APN overlaps that of $\mu$-opioid, but not $\delta$-opioid receptors [32] [34], and that the $\mathrm{N}$-terminal region of Dyn A (1-17) interacts with both $\mu$-opioid and $\delta$-opioid receptors [40] [41] [42].

One study demonstrated that DCE was an important enzyme in Dyn A-induced antinociception and toxicity at the spinal cord level [6]. This indicates that pretreatment with PHMB and ACP would safeguard the integrity of i.t. administered Dyn A (1-17). Another study reported that toxicity ranked in the order of Dyn A (1-17) > Dyn A (1-13) > Dyn A (13-17), whereas LE caused no neuronal toxicity [2]. The present results showed that the antinociceptive potency of 0.3 nmol Dyn A (1-17) under pretreatment with PHMB and ACP was not significantly higher than that with ACP alone. The 2 rats showing the lowest values for antinociceptive potency exhibited subtle lower limb paralysis following administration of $0.3 \mathrm{nmol}$ Dyn A (1-17) under pretreatment with PHMB and ACP, but recovered completely after $24 \mathrm{hr}$. Potency in these two animals was lower than the lowest observed with ACP in the absence of PHMB. This reduction in potency may have resulted from hyperalgesia, as suggested by an earlier study reporting that i.t. administration of high-dose Dyn A (1-17) induced hyperalgesia [43].

Neuropathy was observed in a total of 4 out of 6 rats after i.t. administration of 0.3 nmol Dyn A (1-17) under pretreatment with PHMB and ACP. Both the tail flick and von Frey test could not be used to evaluate allodynia in 2 out of 4 rats which developed neuropathy due to severe and long-lasting paralysis of the tails and lower limbs after administration of 0.3 nmol Dyn A (1-17) under pretreatment with PHMB and ACP. Meanwhile, subtle and transient paralysis occurred in the two remaining rats, and these animals showed the lowest $\mathrm{AUC}_{0-120 \mathrm{~min}}$ values and stimulus intensity in the tail flick and von Frey test, respectively. Two other rats showed no abnormal signs. These may lead to no difference in Dyn A 
(1-17)-induced antinociception and allodynia under pretreatment with ACP between with and without concomitant administration of PHMB. The character and frequency of symptoms of neuropathic pain may depend on the dose of Dyn A (1-17), which would correspond to the concentration of Dyn A (1-17) in the intrathecal space. Indeed, earlier studies have reported persistent allodynia with i.t. administration of high-dose (15 - $50 \mathrm{nmol})$ Dyn A [7] [10]. Further support for this hypothesis comes from evidence that high doses of Dyn A enhance intracellular levels of $\mathrm{Ca}^{2+}$ via simultaneous activation of NMDA and $\kappa$-opioid receptors, whereas low doses activate only $\kappa$-opioid receptors [7].

\section{Conclusion}

In conclusion, the present results showed that inactivation of $\mathrm{A}-$, C-, or P-sensitive enzymes leads to an increase in low-dose Dyn A (1-17)-induced antinociception without signs of allodynia at the spinal level. The antinociceptive potency and induction of allodynia by Dyn A (1-17), Dyn A (1-13), or their peptide fragments depended on their dose and length. The present findings suggest that PIs and other inhibitors of opioid peptide-degrading enzymes may have potential as novel therapeutic compounds for treatment of pain.

\section{Acknowledgements}

The authors would like to thank Professor Jeremy Williams, Tokyo Medical University, for his assistance with the English of the manuscript. A part of this study was supported by JSPS KAKENHI Grant Number 26462385 and 25462453.

\section{Disclosures}

There is no conflict of interest in this study.

\section{References}

[1] Chavkin, C., James, I.F. and Goldstein, A. (1982) Dynorphin Is a Specific Endogenous Ligand of the Kappa Opioid Receptor. Science, 215, 413-415. https://doi.org/10.1126/science.6120570

[2] Hauser, K.F., Knapp, P.E. and Turbek, C.S. (2001) Structure-Activity Analysis of Dynorphin A Toxicity in Spinal Cord Neurons: Intrinsic Neurotoxicity of Dynorphin A and Its Carboxyl-Terminal, Nonopioid Metabolites. Experimental Neurology, 168, 78-87. https://doi.org/10.1006/exnr.2000.7580

[3] Massardier, D. and Hunt, P.F. (1989) A Direct Non-Opiate Interaction of Dynorphin-(1-13) with the N-Methyl-D-Aspartate (NMDA) Receptor. European Journal of Pharmacology, 170, 125-126. https://doi.org/10.1016/0014-2999(89)90149-0

[4] Shukla, V.K., Bansinath, M., Dumont, M. and Lemaire, S. (1992) Selective Involvement of Kappa Opioid and Phencyclidine Receptors in the Analgesic and Motor Effects of Dynorphin-A-(1-13)-Tyr-Leu-Phe-Asn-Gly-Pro. Brain Research, 591, 176 180. https://doi.org/10.1016/0006-8993(92)90994-K

[5] Herman, B.H. and Goldstein, A. (1985) Antinociception and Paralysis Induced by Intrathecal Dynorphin A. The Journal of Pharmacology and Experimental Therapeutics, 232, 27-32. http://jpet.aspetjournals.org/content/232/1/27.long

[6] Tan-No, K., Taira, A., Sakurada, T., Inoue, M., Sakurada, S., Tadano, T., Sato, T., 
Sakurada, C., Nylander, I., Silberring, J., Terenius, L. and Kisara, K. (1996) Inhibition of Dynorphin-Converting Enzymes Prolongs the Antinociceptive Effect of Intrathecally Administered Dynorphin in the Mouse Formalin Test. European Journal of Pharmacology, 314, 61-67. https://doi.org/10.1016/S0014-2999(96)00518-3

[7] Laughlin, T.M., Vanderah, T.W., Lashbrook, J., Nichols, M.L., Ossipov, M., Porreca, F. and Wilcox, G.L. (1997) Spinally Administered Dynorphin A Produces LongLasting Allodynia: Involvement of NMDA but Not Opioid Receptors. Pain, 72, 253 260. https://doi.org/10.1016/S0304-3959(97)00046-8

[8] Long, J.B., Martinez-Arizala, A., Petras, J.M. and Holaday, J.W. (1986) Endogenous Opioids in Spinal Cord Injury: A Critical Evaluation. Central Nervous System Trauma, 3, 295-315. https://doi.org/10.1089/cns.1986.3.295

[9] Long, J.B., Martinez-Arizala, A., Rigamonti, D.D. and Holaday, J.W. (1988) Hindlimb Paralytic Effects of Arginine Vasopressin and Related Peptides Following Spinal Subarachnoid Injection in the Rat. Peptides, 9, 1335-1344.

https://doi.org/10.1016/0196-9781(88)90200-8

[10] Vanderah, T.W., Laughlin, T., Lashbrook, J.M., Nichols, M.L., Wilcox, G.L., Ossipov, M.H., Malan Jr., T.P. and Porreca, F. (1996) Single Intrathecal Injections of Dynorphin A or Des-Tyr-Dynorphins Produce Long-Lasting Allodynia in Rats: Blockade by MK-801 but Not Naloxone. Pain, 68, 275-281. https://doi.org/10.1016/S0304-3959(96)03225-3

[11] Oka, T., Aoki, K., Kajiwara, M., Ishii, K., Kuno, Y., Hiranuma, T. and Matsumiya, T. (1986) Inactivation of [Leu5]-Enkephalin in Three Isolated Preparations: Relative Importance of Aminopeptidase, Endopeptidase-24.11 and Peptidyl Dipeptidase A. NIDA Research Monographs, 75, 259-262.

[12] Hiranuma, T., Kitamura, K., Taniguchi, T., Kanai, M., Arai, Y., Iwao, K. and Oka, T. (1998) Protection against Dynorphin-(1-8) Hydrolysis in Membrane Preparations by the Combination of Amastatin, Captopril and Phosphoramidon. The Journal of Pharmacology and Experimental Therapeutics, 286, 863-869.

[13] Kramer, T.H., Davis, P., Hruby, V.J., Burks, T.F. and Porreca, F. (1993) In Vitro Potency, Affinity and Agonist Efficacy of Highly Selective Delta Opioid Receptor Ligands. The Journal of Pharmacology and Experimental Therapeutics, 266, $577-$ 584.

[14] Akahori, K., Kosaka, K., Jin, X.L., Arai, Y., Yoshikawa, M., Kobayashi, H. and Oka, T. (2008) Great Increase in Antinociceptive Potency of [Leu5]Enkephalin after Peptidase Inhibition. Journal of Pharmacological Sciences, 106, 295-300. https://doi.org/10.1254/jphs.FP0071318

[15] Numata, H., Hiranuma, T. and Oka, T. (1988) Inactivation of Dynorphin-(1-8) in Isolated Preparations by Three Peptidases. The Japanese Journal of Pharmacology, 47, 417-423. https://doi.org/10.1254/jip.47.417

[16] Kitamura, K., Akahori, K., Yano, H., Iwao, K. and Oka, T. (2000) Effects of Peptidase Inhibitors on Anti-Nociceptive Action of Dynorphin-(1-8) in Rats. NaunynSchmiedeberg's Archives of Pharmacology, 361, 273-278. https://doi.org/10.1007/s002109900182

[17] Ajimi, J., Yoshikawa, M., Takahashi, S., Miura, M., Tsukamoto, H., Kawaguchi, M., Kobayashi, H. and Suzuki, T. (2015) Effect of Three Peptidase Inhibitors on Antinociceptive Potential and Toxicity with Intracerebroventricular Administration of Dynorphin A (1-17) or (1-13) in the Rat. Journal of Anesthesia, 29, 65-77. https://doi.org/10.1007/s00540-014-1860-4

[18] Silberring, J., Castello, M.E. and Nyberg, F. (1992) Characterization of Dynorphin A-Converting Enzyme in Human Spinal Cord. An Endoprotease Related to a Dis- 
tinct Conversion Pathway for the Opioid Heptadecapeptide? The Journal of Biological Chemistry, 267, 21324-21328.

[19] Magnusson, K., Hallberg, M., Bergquist, J. and Nyberg, F. (2007) Enzymatic Conversion of Dynorphin A in the Rat Brain Is Affected by Administration of Nandrolone Decanoate. Peptides, 28, 851-858. https://doi.org/10.1016/j.peptides.2006.12.011

[20] Barnes, K. and Turner, A.J. (1997) The Endothelin System and Endothelin-Converting Enzyme in the Brain: Molecular and Cellular Studies. Neurochemical Research, 22, 1033-1040. https://doi.org/10.1023/A:1022435111928

[21] Malmberg, A.B. and Yaksh, T.L. (1992) Isobolographic and Dose-Response Analyses of the Interaction between Intrathecal $\mathrm{Mu}$ and Delta Agonists: Effects of Naltrindole and Its Benzofuran Analog (NTB). The Journal of Pharmacology and EXperimental Therapeutics, 263, 264-275.

[22] Walker, E.A. (2006) In Vivo Pharmacological Resultant Analysis Reveals Noncompetitive Interactions between Opioid Antagonists in the Rat Tail-Withdrawal Assay. British Journal of Pharmacology, 149, 1071-1082.

https://doi.org/10.1038/sj.bjp.0706946

[23] Xie, H., Woods, J.H., Traynor, J.R. and Ko, M.C. (2008) The Spinal Antinociceptive Effects of Endomorphins in Rats: Behavioral and G Protein Functional Studies. Anesthesia \& Analgesia, 106, 1873-1881. https://doi.org/10.1213/ane.0b013e31817300be

[24] Aoki, K., Kajiwara, M. and Oka, T. (1986) The Inactivation of [Met5]-Enkephalin by Bestatin-Sensitive Aminopeptidase, Captopril-Sensitive Peptidyl Dipeptidase A and Thiorphan-Sensitive Endopeptidase-24.11 in Mouse Vas Deferens. The Japanese Journal of Pharmacology, 40, 297-302. https://doi.org/10.1254/jjp.40.297

[25] Yaksh, T.L. and Rudy, T.A. (1976) Chronic Catheterization of the Spinal Subarachnoid Space. Physiology \& Behavior, 17, 1031-1036. https://doi.org/10.1016/0031-9384(76)90029-9

[26] Janssen, P.A., Niemegeers, C.J. and Dony, J.G. (1963) The Inhibitory Effect of Fentanyl and Other Morphine-Like Analgesics on the Warm Water Induced Tail Withdrawl Reflex in Rats. Arzneimittelforschung, 13, 502-507.

[27] Yeomans, D.C. and Proudfit, H.K. (1996) Nociceptive Responses to High and Low Rates of Noxious Cutaneous Heating Are Mediated by Different Nociceptors in the Rat: Electrophysiological Evidence. Pain, 68, 141-150. https://doi.org/10.1016/S0304-3959(96)03177-6

[28] Park, H.J., Marino, M.J., Rondon, E.S., Xu, Q. and Yaksh, T.L. (2015) The Effects of Intraplantar and Intrathecal Botulinum Toxin Type B on Tactile Allodynia in Mono and Polyneuropathy in the Mouse. Anesthesia \& Analgesia, 121, 229-238. https://doi.org/10.1213/ane.0000000000000777

[29] Zhu, Q., Sun, Y., Mao, L., Liu, C., Jiang, B., Zhang, W. and Li, J.X. (2016) Antinociceptive Effects of Sinomenine in a Rat Model of Postoperative Pain. British Journal of Pharmacology, 173, 1693-1702. https://doi.org/10.1111/bph.13470

[30] Kaneko, T., Nakazawa, T., Ikeda, M., Yamatsu, K., Iwama, T., Wada, T., Satoh, M. and Takagi, H. (1983) Sites of Analgesic Action of Dynorphin. Life Sciences, 33, 661-664. https://doi.org/10.1016/0024-3205(83)90589-1

[31] Miura, M., Yoshikawa, M., Watanabe, M., Takahashi, S., Ajimi, J., Ito, K., Ito, M., Kawaguchi, M., Kobayashi, H. and Suzuki, T. (2013) Increase in Antinociceptive Effect of [leu5]Enkephalin after Intrathecal Administration of Mixture of Three Peptidase Inhibitors. The Tokai Journal of Experimental and Clinical Medicine, 38, 62-70. 
[32] Back, S.A. and Gorenstein, C. (1989) Fluorescent Histochemical Localization of Neutral Endopeptidase-24.11 (Enkephalinase) in the Rat Spinal Cord. Journal of Comparative Neurology, 280, 436-450. https://doi.org/10.1002/cne.902800309

[33] Noble, F., Banisadr, G., Jardinaud, F., Popovici, T., Lai-Kuen, R., Chen, H., Bischoff, L., Parsadaniantz, S.M., Fournie-Zaluski, M.C. and Roques, B.P. (2001) First Discrete Autoradiographic Distribution of Aminopeptidase N in Various Structures of Rat Brain and Spinal Cord Using the Selective Iodinated Inhibitor [125I]RB 129. Neuroscience, 105, 479-488. https://doi.org/10.1016/S0306-4522(01)00185-3

[34] Waksman, G., Bouboutou, R., Devin, J., Bourgoin, S., Cesselin, F., Hamon, M., Fournie-Zaluski, M.C. and Roques, B.P. (1985) In Vitro and in Vivo Effects of Kelatorphan on Enkephalin Metabolism in Rodent Brain. European Journal of Pharmacology, 117, 233-243. https://doi.org/10.1016/0014-2999(85)90608-9

[35] Waksman, G., Hamel, E., Fournie-Zaluski, M.C. and Roques, B.P. (1986) Autoradiographic Comparison of the Distribution of the Neutral Endopeptidase "Enkephalinase" and of $\mathrm{Mu}$ and Delta Opioid Receptors in Rat Brain. Proceedings of the National Academy of Sciences of the United States of America, 83, 1523-1527. https://doi.org/10.1073/pnas.83.5.1523

[36] Kuno, Y., Aoki, K., Kajiwara, M., Ishii, K. and Oka, T. (1986) The Relative Potency of Enkephalins and Beta-Endorphin in Guinea-Pig Ileum, Mouse Vas Deferens and Rat Vas Deferens after the Administration of Peptidase Inhibitors. The Japanese Journal of Pharmacology, 41, 273-281. https://doi.org/10.1254/jjp.41.273

[37] Taylor, D.A. (2011) In Vitro Opioid Receptor Assays. Current Protocols in Pharmacology, 55, 4.8.1-4.8.34. https://doi.org/10.1002/0471141755.ph0408s55

[38] Hughes, J., Smith, T.W., Kosterlitz, H.W., Fothergill, L.A., Morgan, B.A. and Morris, H.R. (1975) Identification of Two Related Pentapeptides from the Brain with Potent Opiate Agonist Activity. Nature, 258, 577-580. https://doi.org/10.1038/258577a0

[39] Goldstein, A., Fischli, W., Lowney, L.I., Hunkapiller, M. and Hood, L. (1981) Porcine Pituitary Dynorphin: Complete Amino Acid Sequence of the Biologically Active Heptadecapeptide. Proceedings of the National Academy of Sciences of the United States of America, 78, 7219-7223. https://doi.org/10.1073/pnas.78.11.7219

[40] Chavkin, C. and Goldstein, A. (1981) Specific Receptor for the Opioid Peptide Dynorphin: Structure-Activity Relationships. Proceedings of the National Academy of Sciences of the United States of America, 78, 6543-6547.

https://doi.org/10.1073/pnas.78.10.6543

[41] Mansour, A., Hoversten, M.T., Taylor, L.P., Watson, S.J. and Akil, H. (1995) The Cloned Mu, Delta and Kappa Receptors and Their Endogenous Ligands: Evidence for Two Opioid Peptide Recognition Cores. Brain Research, 700, 89-98. https://doi.org/10.1016/0006-8993(95)00928-J

[42] Naqvi, T., Haq, W. and Mathur, K.B. (1998) Structure-Activity Relationship Studies of Dynorphin A and Related Peptides. Peptides, 19, 1277-1292. https://doi.org/10.1016/S0196-9781(98)00042-4

[43] Rojewska, E., Makuch, W., Przewlocka, B. and Mika, J. (2014) Minocycline Prevents Dynorphin-Induced Neurotoxicity during Neuropathic Pain in Rats. Neuropharmacology, 86, 301-310. https://doi.org/10.1016/j.neuropharm.2014.08.001 


\section{Abbreviations}

A: amastatin,

ANOVA: analysis of variance,

APN: aminopeptidase N,

AUC: area under the curve,

$\mathrm{C}$ : captopril,

CTOP: D-Phe-Cys-Tyr-D-Trp-Orn-Thr-Pen-Thr- $\mathrm{NH}_{2}$,

DCE: dynorphiin-converting enzyme,

Dyn: dynorphin,

$\mathrm{ED}_{50}$ : median effective dose,

$\mathrm{IC}_{50}$ : concentration required to produce $50 \%$ inhibition,

i.c.v.: intracerebroventricular,

i.t.: intrathecal,

LE: [Leu5]-enkephalin,

MPE: maximal possible effect,

MVD: mouse vas deferens,

NEP: neutral endopeptidase-24.11,

NMDA: N-methyl-D-aspartate,

nor-BNI: nor-binaltorphimine dihydrochloride,

NOX: naloxone hydrochloride,

NTI: naltrindole hydrochloride,

$\mathrm{P}$ : phosphoramidon,

PHMB: p-hydroxymercuribenzoate,

PIs: peptidase inhibitors,

S.E.M.: standard error of the mean.

\section{Scientific Research Publishing}

Submit or recommend next manuscript to SCIRP and we will provide best service for you:

Accepting pre-submission inquiries through Email, Facebook, LinkedIn, Twitter, etc. A wide selection of journals (inclusive of 9 subjects, more than 200 journals) Providing 24-hour high-quality service

User-friendly online submission system

Fair and swift peer-review system

Efficient typesetting and proofreading procedure

Display of the result of downloads and visits, as well as the number of cited articles Maximum dissemination of your research work

Submit your manuscript at: http://papersubmission.scirp.org/

Or contact pp@scirp.org 